\title{
Yapay Sinir Ağı Yöntemlerinin Tekstil Sektöründe Kullanım Uygulamaları
}

\author{
Mustafa ÇÖREKCIOĞLU ${ }^{* 1}$, Emel ERCAN ${ }^{1}$, Sultan ARAS ELİBÜYÜK ${ }^{1}$ \\ ${ }^{1}$ Ozanteks Tekstil San. ve Tic. A.Ş, 20085, Denizli/Türkiye
}

(Alınış / Received: 21.02.2021, Kabul / Accepted: 12.07.2021)

\section{Derleme Makalesi}

\section{Anahtar Kelimeler \\ Yapay Sinir Ağları 1, Tekstilde YSA 2, \\ YSA Çeşitleri 3, \\ YSA Uygulamaları 4}

\begin{abstract}
Özet: Günümüzde tekstil ürünlerine olan talebin artması ve müşteri beklentilerinin yükselmesi ile birlikte, tekstil sektöründe müşteriye sunulan süreç, ürün ve hizmet faktörlerinde gelişim zorunlu bir ihtiyaç haline gelmiştir. Bu gelişimi sağlayabilecek araștırma yöntemlerinden birisi de yapay sinir ağlarıdır (YSA). YSA, insan beyninin basitleştirilmesi sonucunda türetilen algoritmik yapıları temsil etmektedir. YSA yöntemi beyindeki nöronların matematiksel modellere dönüştürülmesini kapsar. $\mathrm{Bu}$ sayede, genelleme, tahmin yürütme ve problem çözümü işlemleri gerçekleştirilebilir. Bu çalışmada yapay sinir ağı yöntemlerinin tekstil sektöründe ki kullanımlarına yönelik literatür çalışmaları araştırılmıştır. Literatür araştırmalarında tekstil sektöründe yapay sinir ağlarının, iplik parametrelerinin tahmin edilmesinde, dokuma aşamasında, terbiye bölümünde, kumaş konfor parametrelerinin tahmin edilmesinde kullanıldığı çalışmalara rastlamak mümkündür.
\end{abstract}

\section{Usage Applications of Artificial Neural Network Methods In Textile Industry}

\section{Keywords}

Artificial Neural Networks 1, ANN in textile 2,

ANN types 3,

ANN Applications 4

\begin{abstract}
Today, with the increasing demand for textile products and the increase in customer expectations, improvement in the process, product and service factors offered to the customer in the textile sector has become a necessary need. One of the research methods that can provide this development is artificial neural networks (ANN). ANN represents algorithmic structures derived as a result of simplifying the human brain. The ANN method involves the conversion of neurons in the brain into mathematical models. In this way, generalization, prediction and problem solving processes can be performed. In this study, literature studies on the use of artificial neural network methods in the textile industry have been investigated. In the literature researches, it is possible to come across studies in which artificial neural networks are used in the estimation of yarn parameters, in the weaving phase, in the finishing department, in the estimation of fabric comfort parameters in the textile sector.
\end{abstract}

\section{Giriş}

Günümüzde farklı sektörlerdeki problemlerin çözümü için çeşitli yöntemler kullanılmaktadır. Yapay sinir ağları (YSA) teknolojisi bu yöntemler içerisindeki en yenilerden biridir ve birçok alanda başarıyla uygulanmaktadır. Yapay sinir ağı mantıklı bir programlama yöntemi olup, insan beynindeki çalışma düzeneğini taklit edip geliștirmeyi ve insan beyninin biyolojik olarak yapabildiği bașlıca davranıșları uygun bir yazılım ile gerçekleștirmeyi hedeflemektedir.
Yapay sinir ağları, karar hızı açısından insan beyni ile henüz kat edememiş olmalarına rağmen, karmaşık yapıların sonuçları gerçekleşebilmesi nedeniyle gün geçtikçe uygulama alanları artmaktadır [1]. Yapay sinir ağlarına herhangi bir örnek giriş verisinin tanıtılabilmesi ve bunun daha sonra kullanılabilmesi için verinin ağda nasıl temsil edildiğinin, nerede saklandığının ve nasıl geri alındığının bilinmesi gerekmektedir.

Yapay sinir ağları üzerine yapılan çalışmalar gelișen teknolojiye paralel olarak artmaktadır. Özellikle 
tahminleme, kontrol ve doğrulamaya yönelik ağlar pratik anlamda çok faydalı olmaktadır. Yeni veri girişine izin veren ağlar eski örnekleri değerlendirerek yeni giriș için bir çıktı değer oluşturmaktadır. Yöntem sayesinde öğrenebilme, hafızaya alabilme, öğrenilen verilerden yeni bilgiler edinebilme, değişkenler arasında ilişkiyi belirleyebilme, karar alma ve sonuç çlkarma gibi beceriler kazanılmaktadır.

$\mathrm{Bu}$ çalışma kapsamında yapay sinir ağı yönteminin tekstil sektöründeki kullanım alanları ve faaliyetleri incelenmiş ve çalışmalar derlenmiştir.

\section{Yapay Sinir Ağları}

YSA, insan beyni yapısının basitleştirilmiş bir konseptinden türetilen algoritmik yapılar olarak tanımlanmaktadır. Yapay sinir ağları bulanık mantık/bulanık kontrol algoritmaları ve genetik algoritmalar gibi yapay zekâ ile hesaplama yöntemleri ailesine aittirler [2]. Bu yöntemlerin tamamı temelde yatan sistem veya süreç için herhangi bir tipte bir modelin ön varsayımı olmadan, belirli bir soruna optimal veya en uyguna yakın çözümler bulabilmek için yinelemeli, doğrusal olmayan bir araştırmayı paylaşırlar [3]. Bilginin öğrenilerek elde edilmesi ve bilgi sağlanabilirliğinin nöronlar (sinir hücresi) arası ağırlıklar ile sağlanabilmesi özellikleri sayesinde YSA yöntemi, beyne benzer [4]. YSA yönteminde biyolojik nöron yapısı, matematiksel modellere dönüştürülürken şu varsayımlar kullanılmıştır:

- Nöronlar sayesinde bilgi işleme gerçekleştirilir.

- Nöronlar arasında ilişkiyi sağlayan bağlantılar sayesinde sinyaller gönderilir.

- Her bir bağlantıda bir ağırlık değeri bulunmaktadır. Gerçek nöronlardaki sinyal geçişinin üretimi de bu değer ile sağlanır.

- Sinir ağı içerisindeki her bir nöron için bir aktivasyon fonksiyonu olur. Genellikle bu fonksiyon doğrusal değildir. Nöron çıkıș sinyali de bu fonksiyonun giriş değerine göre belirlenmektedir [5].

Birçok YSA türü, çeşitli uygulama alanlarında başarılı bir şekilde kullanılmaktadır [4]. YSA işlevleri temelde 2 şekilde belirtilmektedir:

1. Fonksiyon yaklaşımı: Sistem girdi-çıktı modellemesi ve tahmininde kullanılmaktadır.

2. Sınıflandırma: Örüntü tanıma / sınıflandırma problemlerinde kullanılmaktadır [6].

YSA yöntemi aşağıda belirtilen özellikler sayesinde farklı alanlarda başarıyla uygulanabilmiştir:

- Doğrusal olmaması sebebiyle tüm sistemde eş zamanlı çalışmanın mümkün olması ve hızı arttırması,

- Öğrenme yeteneği zenginleștirmesi,

- Farklı problemlerde kolaylıkla uygulanabilmesi,

- Öğrenme süreci sonrasında daha az bilgiye ihtiyaç duyulması,

- Genelleme yapabilme becerisi,
- Paralel yapılar sayesinde hızlı işlem yapılabilmesi,

- Zor matematiksel modellerin hızla çözülebilmesi,

- Hata toleransı yüksek olduğu için gürültü(hata) ve eksik veri bulunmasına rağmen anlamlı biçimde doğru çıtıtı üretilebilmesi [7].

Her yöntemde olduğu gibi YSA yönteminin de faydaları ve sakıncaları bulunmaktadır. YSA' nın faydaları şu şekildedir:

- YSA eğitilirken kendilerine gösterilen örneklerden genelleme yapabilirler. $\mathrm{Bu}$ sayede bu örneklere yönelik bilgi üretebilirler.

- Matematiksel modele gereksinim duyulmaz ve veri eğitimi aşamasında varsayım yapılması gerekli değildir.

- Verilerin kullanımı ile bilinmeyen ilişkiler akıllı biçimde hemen ortaya çıkarılabilir.

- Sistemde oluşabilecek hatalara karşı geleneksel bilgisayar sistemleri oldukça duyarlı hale gelmektedir. Ancak YSA yönteminde bir veya birden fazla nöron zarar görse dahi sistem, geleneksel bilgisayar teknolojisindeki kadar etkilenmemektedir. Çünkü YSA yönteminde hata toleransı mevcuttur.

- Ağın parametrelerinde (ağırlık katsayısı gibi) değişiklik olması durumunda, somut bir problem sonucuna ulaşabilmek için ağ kendini uyarlayabilmektedir.

- Ağlar doğrusal olmadığı için doğrusal olmayan karmaşık problemlerde çözüm kolaylıkla bulunabilir. Böylece doğrusal model çözüm yöntemlerine göre üstünlük sağlamaktadır [8].

Yapay sinir ağının sakıncaları aşağıdaki gibidir:

- Problem için uygun bir ağ yapısı belirleme süreci zordur. Bu süreçte ağ yapısı genellikle deneme-yanılma yöntemi ile belirlenmektedir ve bu işlem uzun sürebilmektedir.

- $\quad$ Eğer probleme uygun bir ağ yapısı seçilemez ise, problem çözümünün bulunamaması veya düşük performanslı çözümler ile karşılaşıla bilinir. Ayrıca elde edilen çözümün en iyi olduğu garanti değildir.

- Bazı ağlar için ağın parametre değerleri kullanıcı tecrübesine bağlı olup, bir kurala göre belirlenmediği için çözümlere ulaşmada sorun yaşanabilir.

- Problem ağının gösterimi oldukça önemlidir. YSA yönteminin çalışabilmesi için sadece sayısal veriler kullanılmaktadır ve problem sayısal değerlere çevrilmelidir.

- Belirlenen ağın eğitilme süresinin ne zaman bitirileceği net değildir.

- Eğitimdeki hata toleransı belirli bir değer altında ise eğitim süreci yeterli görülür [8]. 
Yapay sinir ağları yapısal açıdan üç başlık altında incelemek mümkündür;

a. İleri beslemeli YSA: Bu tür ağ yapısında sinir hücreleri birbirini takip edecek şekilde arka arkaya beslenmektedirler. Ağda bulunan her bir tabaka, çıtılarını hesaplamakta ve bir sonraki ağa bu çıktıları iletmektedir [11]. İleri beslemeli ağ yalnızca önceki katmanlardan girdi alan bir sistemdir. Çıktıdan girdiye herhangi bir geribildirim katmanı yoktur [12]. Şekil 1' de İleri Beslemeli YSA modeli yer almaktadır.

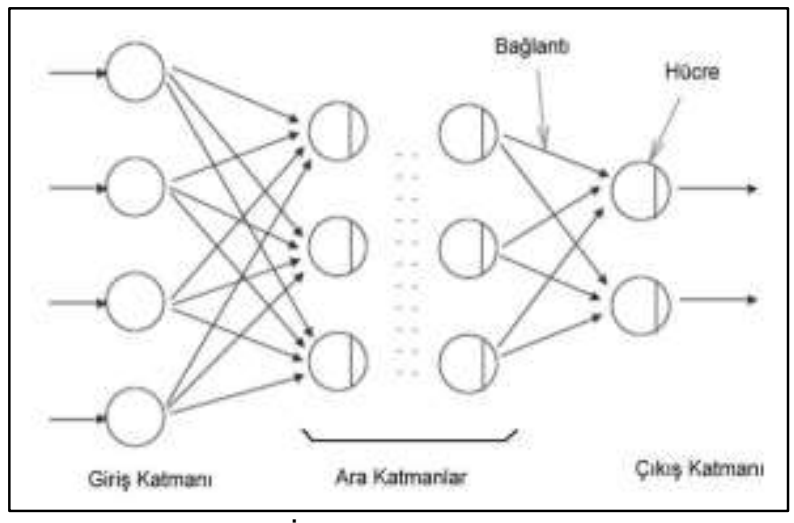

Şekil 1. İleri Beslemeli YSA [9]

b. Geri beslemeli YSA: Bu tür ağlarda diğerlerinin aksine, tabakalar arasındaki bağlantıya ek olarak tabakadaki her bir sinir hücresi diğerleriyle bağlantılıdır [11]. Şekil 2' de Geri Beslemeli YSA modeli yer almaktadır.

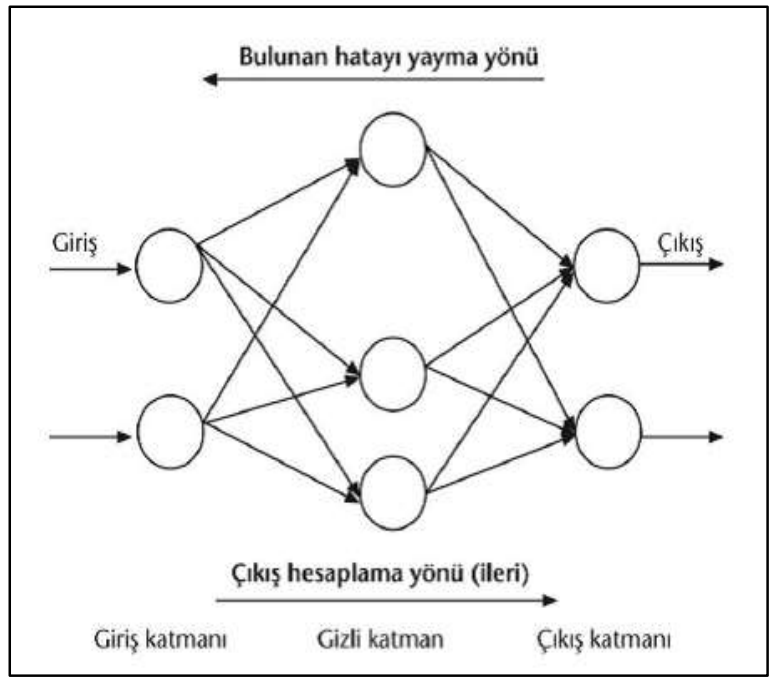

Şekil 2. Geri Beslemeli YSA [9]

c. İleri beslemeli geri yayılmalı YSA: Bu tür ağ yapısında, geri yayılma kuralı, ağ içindeki mevcut hata düzeyine göre her bir tabakadaki ağırlıkları yeniden hesaplamak için kullanılmaktadır. Aynı tabakadaki sinir hücreleri arasında bağlantı mevcut değildir. Tabakadaki her bir sinir hücresi bir ileri tabakadaki her bir sinir hücresine ayrı ayrı bağlıdır ve bunların giriş değerini vermektedir [11]. İleri besleme ve geriye yayılım kombinasyonu ağı daha dirençli, daha az karmaşık ve daha hızlı eğitilebilir hale getirmektedir [12].

\section{Yapay Sinir Ağlarının Tekstil Sektöründe Kullanımı}

1990 yllından itibaren tekstil sektöründe YSA uygulamaları giderek daha popüler hale gelmeye başlamıştır. YSA yöntemi ile gün geçtikçe karmaşık mühendislik problemlerinin başarıyla çözülebileceği kanıtlanmıştır. Bu kapsamda birçok araştırmacı çok parametreli ve doğrusal olmayan bir problem ile karşılaştığında çözüm bulmak için YSA yöntemlerine başvurmuştur [10]. Tekstil sektöründe YSA yöntemlerinin kullanıldığı alan bazlı çalışmaları içerikleri aşağıda aktarıldığı gibidir.

Yapay sinir ağlarının avantajının yanında, kullanımının tecrübeye dayalı olması, eğitiminin uzun sürebilmesi, çalışmalar sırasında problemlere yaklaşık sonuçlar üretmek yerine en iyi sonuçlara odaklanması gibi dezavantajları da bulunmaktadır. Diğer tahmin yöntemleri gibi bir model yapısı oluşturmaz ve parametre tahminlerini vermez [14]. $\mathrm{Bu}$ dezavantajlara rağmen yapay sinir ağlarının tahmin, sınıflandırma, veri ilişkilendirme, veri filtreleme, tanıma ve eșleștirme, teșhis ve yorumlama fonksiyonlarını gerçekleştirebileceği alanlardaki uygulamaları sanayi alanlarında görülmektedir.

\subsection{Lifler}

YSA yöntemi, model tanıma ve nesne sınıflandırma ile ilişkili birçok problemin çözümünde giderek daha fazla kullanılmaktadır.

She vd. (2002) çalışmalarında YSA yöntemini kullanarak hayvan lifi olan merinos ve tiftik liflerini sinıflandırmışlardır [15]. Cheng vd. (1999), Xu vd. (2000); Kang vd., (2002) çalışmaları kapsamında ham pamuk liflerinin renklerini sınıflandırmak amacıyla YSA yöntemlerini kullanmışlardır $[15,16,17]$. Mwasiagi vd. (2009) pamuk tiftiğini sınıflandırmak için YSA yönteminden faydalanmışlardır [18]. Sentetik lifler söz konusu olduğunda YSA yöntemi Allan vd. (2001) tarafından polipropilen lifinin işlenmesi sırasında yapı ve özellikleri tahmin edip seçilmiş liflerin üretim kontrol parametrelerinin belirlenmesinde [19], Kuo, (2004) tarafından ise eriyikten çekilmiş liflerin özelliklerinin tahmin edilmesinde kullanılmıştır [20].

Toprakçı (2018) çalışmasında 13 farklı harman ile 4 farklı numarada üretilen karde pamuk ipliğinin lif ve iplik özellikleri incelenmiş ve lif özellikleri kullanılarak, iplik özellikleri tahmin edilmeye çalışılmıştır. Tahmin edilmeye çalışılan iplik özellikleri düzgünsüzlük, ince yer sayısı, kalın yer sayısı, neps sayısı, tüylülük, kopma uzaması ve mukavemet verileri olarak belirlenmiştir. Tahminleme sürecinde çoklu regresyon analizleri ve YSA yöntemlerinden faydalanılarak denklemler oluşturulmuştur. Elde edilen modellerin istatistiksel yönden önemli olduğu 
görülmüștür. Ayrıca YSA yönteminden elde edilen model ile iplik özelliklerinin daha iyi şekilde tahminlendiği belirlenmiștir [21].

\section{2. İplikler}

Zeng ve ark. (2004), YSA yöntemi ile hava jeti makinesinde eğrilmiş sentetik ipliklerin mukavemetini tahminlemeye çalışmışlardır. Çalışma kapsamında öncelikle nümerik simülasyon yöntemi kullanılarak düze parametrelerinin mukavemete olan etkisi incelenmiștir. Sonrasında Matlab programı yardımıyla YSA yönteminin geri yayılma algoritması kullanılarak mukavemete etkisi olan düze parametreleri sınırlandırılmıştır. Uygulama sonucunda YSA ile tahmin edilen iplik mukavemet değerlerinin ölçülen değerlere oldukça yakın olduğu görülmüştür. Elde edilen determinasyon katsayısının $\left(R^{2}=0,98\right)$ yüksek değerde bulunması ile de öngörülen değerlerin doğruluğu teyit edilmiştir [22].

Majumdar ve ark. (2005) çalışmalarında doğrusal regresyon, yapay sinir ağı ve nöro-bulanık modellerini kullanarak rotor ipliklerinin kopma uzamasını tahmin etmeye çalışmışlardır. Tahmin modellerinde girdi parametreleri olarak yüksek hacimli cihaz ve iplik numarasıyla ölçülen pamuk lifi özellikleri kullanılmıștır. Tahmin edilen kopma uzaması değerlerinin doğruluğu incelendiğinde yapay sinir ağı ve nöro-bulanık modelleri ile elde edilen sonuçların regresyon modeline göre daha iyi olduğu bulunmuştur. İplik numarası ve pamuk lifi özelliklerinin openend iplik uzamasına göreceli önemi incelenmiștir. İplik numarası ve pamuk lifi mikronerinin rotor ipliklerinin kopma uzamasını etkileyen baskın girdi faktörleri olduğu belirlenmiştir $[23,24]$.

\subsection{Kumaşlar}

Tsai ve ark. (1995) çalışmalarında farklı kategorilerde sınıflandırılmış kumaş kusurlarını belirlemek amacıyla çok katlı yapay sinir ağı yöntemini kullanmışlardır. Dokuma sırasında tespit edilebilme olasılığı yüksek olan dört tür kumaş hatası yapay sinir ağına öğretilmiştir. Kumaş hatalarının tespit edilebilmesi için uzaktan algılama metodu kullanılmıştır. Yapay sinir ağı ile kumaş kusurları doğru tespit edilmiș ve sınıflandırılmıștır [25].

Tsai ve Hu (1996) yaptıkları çalışmada yapay sinir ağlarından geri yayılma algoritmasını kullanarak, genellikle kumaşlarda hata olarak bulunan eksik uçları, eksik atkıları, yağlı kumaşı ve kırılmış kumaşı tespit etmeye çalışmışlardır. Uygulamada kumaşlar alttan aydınlatılmış cam bir yüzey üzerine serildikten sonra, kamera ile kumaş görüntüleri görüntü işleyiciye gönderilmiştir. Bilgisayara gönderilen bu görüntüler sayesinde hatalı kumaş görüntüsü işlenmiş ve Fourier dönüșümü kullanılarak spektrum elde edilmiştir. Kumaşta hata tespit edildiğinde spektrumun belirli pozisyonlarına karşılık gelen yoğunlukların değiştiği görülmüştür. Bu yoğunluklar karakteristik parametreler olarak belirlenmiş ve YSA' da öğrenme için kullanılarak kumaş hataları tanımlanmıștır [26].

Bahlmann ve ark. (1999) çalışmalarında otomatik olarak tekstil dikişlerinin kalite kontrolünün yapılabilmesine yönelik bir yöntem geliştirerek üretim maliyetlerini düşürmeyi hedeflemişlerdir. Yöntemde YSA kullanılarak uygun bir görüntü edinebilme ayarı, dikişlerin yerini belirleme, dikişlerden bir özellik ortaya çıkarma ve özellik sınıflandırması yapılmıştır. Uygulama sonucunda \%80 olarak hesaplanan doğru sınıflandırma değeri ile sınıflandırmanın iyi yapıldığ $\mathrm{l}$ kabul edilmektedir. Çalışma kapsamında 200 dikiş sınıflandırılarak sistem performansı ölçülmüştür. Elde edilen çıtılar ve uzman bir kişinin cevapları kıyaslandığında doğruluk seviyelerinin aynı olduğu belirlenmiştir. YSA ile yapılan sinıflandırma 1 sn de tamamlanırken uzmanın ihtiyaç duyduğu zamanın daha fazla olduğu görülmüștür [27].

Kargı (2013) çalışmasında çoklu doğrusal regresyon (MLR), yapay sinir ağı modeli olan çok katmanlı algılayıcı (MLP) ve radyal tabanlı fonksiyon ağ (RBFN) modelleri kullanarak kumaş üretim sürecinde meydana gelen atkı hatalarını tahmin etmeye çalışmıştır. Öncelikle veri dağılımının normal olduğu ve bağımsız değişkenler arasında çoklu doğrusal bağlantı problemi olmadığı tespit edilmiş ve bir bütün olarak anlamlı olduğu sonucuna varılmıștır. İlk model olan MLR uygulamasında; kumaş metresi, makine devir hızı, salon randımanı, iplik mukavemeti, atkı iplik numarası, atkı iplik cinsi, tezgâh tipi ve örgü tipi değişkenlerinin atkıdaki hata sayısı üzerinde etkili olduğu tespit edilmiştir. MLP uygulandığında ise 13-61 ağ modelinin optimum modeli veren ağ yapısında olduğu ve bu sayede modelin 0,93 oranında doğru tahmin yapabileceği belirlenmiştir. İleri beslemeli sinir ağı yapısındaki RBFN modeli uygulaması sonucunda ise 50-100 ağ modelinin optimum olduğu belirlenmiştir. Uygulanan üç modele göre tahmin performanslarına incelendiğinde şirket için en iyi modelin MLP olduğu belirlenmiştir [7].

\subsection{Boyama ve diğer tekstil işlemleri}

Doğmuş ve ark. (2005) yapmış oldukları çalışmada, yapay sinir ağı kontrol yöntemi kullanılarak tekstil fabrikalarının bağıl nem kontrolü yapmışlardır. Bu çalışmayı yapabilmek için boyutları $60 \times 60 \times 110 \mathrm{~cm}$ olan bir deney düzeneği hazırlamışlardır. Ortamın bağıl nemi \%56 iken istenilen değerlere ulaşmak zaman alıyorken, yapılan yeni düzenekle bağıl nem değeri \%70 olarak seçildiği zaman 125 saniye gibi kısa bir sürede istenilen bu değere ulaşmışlardır. Sistem kararlı halde çalışırken sisteme bozucu etkiler uygulandığında sistemde istenilen set değeri \%0,5 hata ile elde etmişlerdir. Sistemdeki pompanın çalışma konumu otomatik olup, açma/kapama șeklinde olmadığı için, ortama ihtiyaç miktarı kadar nem verilmiştir. Sonuçta daha az hatalı sonuç elde etmişlerdir [28]. 
Erol ve Başlıgil (2005) yapmış oldukları çalışmada, AHP ve YSA yöntemleri dokuz kriter ve beş alternatifli yazılım seçim problemine Expert Choice ve NeuroSolutions programlarında uygulamıșlar ve sonuçları analiz edilerek karşılaştırmışlardır. Ayrıca yapılan bu çalışmada seçim problemi için çok katmanlı YSA' nın farklı topolojilerde bulduğu sonuçları da değerlendirmişlerdir [29].

Nasiri ve ark. (2006) yapmış olduğu çalışmanın amacı polyester yüksek sicaklık (HT) boyamada dispers boyaların konsantrasyonu, sıcaklığı ve zamanının bir fonksiyonu olarak renk verimini modellemek için istatistiksel regresyon, bulanık regresyon ve Yapay Sinir Ağını (YSA) araştırmış, uygulamış ve karşılaştırmıştır. Elde edilen modellerin kestirim gücü MSE değeri ile değerlendirmişlerdir. Sonuçlar, istatistiksel regresyona dayalı modelin kabul edilmesi için gerekli koşulları karşılamadığını göstermiştir. Bununla birlikte, minimum MSE' ye sahip YSA modeli, bulanık regresyona dayalı modelden daha iyi bir tahmin kabiliyeti göstermiştir [30].

Yürük (2006) yapmış olduğu çalışmada, buruşmazlık apresi uygulanmış pamuklu kumaşlarda kullanılan kimyasal maddenin ve işlem koşulunun kopma mukavemeti, buruşma açısı ve aşınma dayanımı üzerine etkisi araştırmıştır. Çalışmada 24 farklı kumaşa tek bir buruşmazlık reçetesi uygulanmış ve kumaşların kopma mukavemeti, aşınma dayanımı ve buruşma açısı ölçümlerini yapmıştır. Ardından yapay sinir ağı yöntemi ile kumaşın özellikleri ile buruşmazlık işlemindeki kopma mukavemeti, aşınma dayanımı ve buruşma açısı değerlerinin değişimi arasında ilişkilendirme yapmıştır [31].

Hasani ve Shanbeh (2010) çalışmasında çeşitli yazlık örme tişörtler için elde edilen Kawabata Değerlendirme Sistemi (KES) parametrelerinden toplam tuşe değerinin dolaylı olarak belirlenmesi için matematiksel bir yöntem olan Ağırlıklı Öklid Mesafesi uygulamışlardır. Yöntemde, kumaş tuşesi ile ilgili çok değişkenli ağırlık, herhangi bir kaynak olmaksızın objektif ölçümlerden subjektif değerlendirmeye kadar belirlenmiştir. Her bir numunenin KES sisteminde girdi olarak ölçülen kumaş mekanik özelliklerine dayalı yazlık örme tişörtlerinin tuşe değerlerinin tahmin edilmesi amacıyla öngörücü modeller oluşturmak için geri yayılım öğrenme algoritmasına sahip yapay sinir ağı ve çoklu doğrusal regresyon algoritması kullanılmıştır. Tuşe değeri ise matematiksel model kullanılarak istenen çıktı olarak tahmin edilmiştir. Optimize edilmiş modellerin tahmin gücü hesaplanmış ve karşılaştırılmıştır. Elde edilen sonuçlar, yapay sinir ağı modelinin tuşe değerini tahmin etmede çok daha etkili olduğunu ve çoklu doğrusal regresyon modeline kiyasla daha iyi performans sağladığını ortaya koymuştur [32].

Ierace ve ark. (2010), bir tekstil işletmesindeki bakım uygulamaları alanında YSA modeli çalışmıştır. Bu makale, bir tekstil şirketinde Yapay Sinir Ağlarına (YSA) dayalı bir Durum Bazlı Bakım (Condition-Based Maintenance -CBM) yaklaşımının benimsenmesinden kaynaklanan faydaların değerlendirilmesine ilişkin gerçek bir vaka çalışmasını ele almaktadır. CBM, bakım yapılması kararının, makinanın gerçek durumuna bakarak verilmesini sağlayan bir yöntemdir. Makinaya ait belirli parametrelerin (gözle inceleme, performans verileri, vibrasyon verilerini ve planlı test sonuçları) izlenmesi sonucu, makinada performans düşüklüğü veya beklenmedik bir arızaya sebep olma olasılığı bakım yapılması gerektiğini belirler. Bu çalışmadaki CBM' nin konusu, dokuma ve örme kumaşların kurutulması ve terbiye edilmesi amacıyla kullanılan ramöz makinesidir. Ramöz makinasındaki en kritik bileşenlerinden biri kumaşı germek ve ona istenilen özelliği kazandırmak için kullanılan çekme zinciridir. Çekme zincirinin verimliliği, enerji tüketimini güçlü bir şekilde etkileyen sürtünme faktörüne bağlı olduğundan, bu zincirin elemanlarının yağlama durumu makine için kritiktir. Bu çalışma, güç tüketimi ve kumaş özellikleri gibi doğrudan ölçülebilir parametreleri kullanarak yağlama koşulunun tahminini desteklemek için bir sistem tanımlamayı amaçlamıştır [33].

Sarıdeli (2010) çalışmasında, yapay sinir ağı ve bulanık mantık yöntemlerini kullanarak iki farklı renkte reçete tahmini yapmiştır. Her iki yöntem sonucunda elde edilen veriler karşılaştırılmış ve laboratuvar koşullarında gerçekleştirilen deneyler ile farklı parametrelerdeki sapmaların renk farkına olan etkisi gözlemlenmiştir. Kumaş boyama sürecinde düzgünlük ve tekrarlanabilirliği etkileyen tuz miktarı, alkali miktarı, boyama süresi, boyama sıcaklığı ve flotte oranı parametreleri deneylerde girdi olarak değerlendirilmiştir. Laboratuvar koşullarında boyamalar sonucu elde edilen verilerin yapay sinir ağları olan RBF (Radial Basis Function-Radyal Tabanlı Fonksiyon) ve MLP (Multi Layer Perceptron - Çok Katmanlı Algılayıcı) yöntemleri ile bulanık mantık uygulamasinda ise ANFIS (Adaptive Neuro-Fuzzy Inference System- Uyarlanabilir Nöro-Bulanık Çıkarım Sistemi) yöntemi denenmiştir. Renk reçetesinin tahmin edilebilmesi için farklı tekrar sayılarında farklı reçetelerle laboratuvarda ve işletmede boyama denemeleri yapılmıştır. Tüm uygulamalarda, eğitimde kullanılan veri sayısı arttırıldıkça hata değerlerinde azalma görülmüștür. RBF yönteminin diğer uygulamalara kıyasla daha kullanışlı ve daha başarılı olduğu belirlenmiștir [34].

Majumdar (2011) Çalışmada 27 adet kumaş incelenmiştir. İçlerinden rastgele seçilen 22 adet kumaştan elde edilen veriler eğitim seti verileri olarak, geri kalan 5 adet kumaștan elde edilen veriler ise deney seti verileri olarak kullanmışlardır. Çalışmanın sonunda, sinir ağından elde edilen ısıl iletkenlik değerleri ile ölçülen değerleri karşılaştırmış ve geliştirilen sistemin 0.95 'in üstünde bir korelasyon katsayısı ile kumaşların ısıl iletkenliğini tahmin edebildiği görmüștür [35].

Huang ve Fu (2018) çalışmalarında görüntü işleme ve makine öğrenme yöntemleri kullanarak boncuklanma değerlendirmesine dayalı olarak keçenin tekstil sınıflandırması yapmışlardır. Görüntü işlemede birinci yöntem olarak Gauss filtreleme ile 
birleştirilmiş ayrık Fourier dönüşümü, ikinci yöntemde ise Daubechies dalgacıkları kullanılmıştır. Ayrıca, tekstil boncuklanmasını arka plandan bölümlere ayırmak için ikileme yapılmıştır. Tekstil için bir veri tabanı oluşturmak amacıyla tekstil görüntü bilgilerinin temel özelliklerini çıkarmak için morfolojik ve topolojik görüntü işleme yöntemleri uygulanmıştır. Makine öğrenme yöntemleri olarak da yapay sinir ağı (YSA) ve destek vektör makinesi (DVM) kullanılarak, tekstil sınıflandırma problemi objektif olarak çözülmüştür [36].

\section{Sonuç}

Doksanlı yıllardan başlayarak, sürekli artan sayıda YSA uygulaması, karmaşık ve çok değişkenli tekstil sorunlarına çözümler sağlamıştır. Tekstil camiası bu güçlü araca aşina olmuş ve ona her geçen gün daha fazla güvenmektedir. Kişisel bilgisayarların hesaplama gücünün sürekli artması, YSA kullanımının gerektirdiği hesaplama maliyetinin dezavantajını azaltmaktadır. Bu nedenle, YSA' nın karmaşık tekstil problemlerinin çözümüne katılım oranlarını artırmaları ve tekstil alanında tasarım ve bilgisayar destekli mühendislik kavramlarını desteklemeleri beklenmektedir.

Bu çalışma kapsamında, literatürde tekstil sektöründe uygulanan yapay sinir ağları yöntemlerinin uygulamaları incelenmiștir. Tekstilde yapay sinir ağlarının, pamuk liflerinin sınıflandırılması probleminde, bazı ipliklerin üretim kontrol parametrelerinin belirlenmesinde, lif özelliklerinin tahmin edilmesinde kullanıldığı görülmektedir. YSA' nın kumaş üretim proseslerinde dokuma aşamasında ve görüntü işleme ile kalite kontrol adımlarında da kendine yer bulduğu görülmektedir. Renk reçetelerinin tahmin edilmesinde kullanılan YSA, ayrıca buruşmazlık apresi uygulanmış kumaşların performans kriterlerinin değerlendirilmesinde de kullanılmıştır. PET boyama şartlarının modellenmesinde de kullanılan YSA, kumaşların dikiş sınıflandırılması ve dikiş performansının tahmin edilmesinde de kendisine yer bulmayı başarmıştır. Kumaşların konfor özelliklerinin tahmin edilmesinde ve ısıl dirençlerinin değerlendirilmesinde de çeşitli uygulamalara rastlamak mümkündür. İncelenen çalışmalarda yapay sinir ağı yöntemlerinin tekstil sektöründe başarılı bir şekilde uygulanabildiği ve başarılı sonuçlar alındığı görülmüştür.

\section{Teşekkür}

Bu çalışma, TÜBİTAK TEYDEB 2244 Sanayi Doktora Programı 119C070 nolu proje kapsamında sürdürülebilir ürünler geliştirilmesine destek vermektedir.

\section{Kaynakça}

[1] Efe Ö.M., Kaynak, O. 2000. Yapay Sinir Ağları ve Uygulamaları. Boğaziçi Üniversitesi, Yayın No: $696-148$ s
[2] Zadeh, L. 1994. Soft Computing and Fuzzy Logic, IEEE Software, vol. 11, no.1-6, pp. 48-56.

[3] Keeler, J. 1992. Vision of Neural Networks and Fuzzy Logic for Prediction and Optimisation of Manufacturing Processes, In: Applications of Artificial Neural Networks III, vol. 1709, pp. 447456

[4] Haykın, S. 1999. Neural Networks: A Comprehensive Foundation, New Jersey

[5] Fausett, L. 1994. Fundamentals of Neural Networks, Prentice Hall International, London

[6] Lippman, R.P. 1987. An İntroduction To Computing With Neural Nets. IEEE ASSP Magazine, pp. 4-22.

[7] Kargı, V.S. 2013. Yapay Sinir Ağ Modelleri Ve Bir Tekstil Firmasında Uygulama. Uludağ Üniversitesi Sosyal Bilimler Enstitüsü Ekonometri Anabilim Dalı Yöneylem Bilim Dalı, Bursa

[8] Elmas, Ç., 2004. Yapay Zekâ, Popüler Bilim, Sayı: 124.

[9] Şengöz, N., 2017. Yapay Sinir Ağları. Erişim Tarihi: 15.02.2021. İnternet Adresi: https://www.derinogrenme.com/2017/03/04/y apay-sinir-aglari/

[10] Vassiliadis,S., Rangoussi,M., Cay, A., Provatidis, C. 2010. Artificial Neural Networks and Their Applications in the Engineering of Fabrics, Woven Fabric Engineering, Polona Dobnik Dubrovski (Ed.), 111-134, ISBN: 978-953-307-194-7

[11] Özdemir H. 2013. Yapay Sinir Ağları ve Dokuma Teknolojisinde Kullanımı. Tekstil Teknolojileri Elektronik Dergisi, 7(1), 51-68

[12] Bhattacharjee D., Kothari V. K. 2007. A Neural Network System for Prediction of Thermal Resistance of Textile Fabrics. Textile Research Journal, 77, 4-12.

[13] She F.H., Kong L.X., Nahavandi S., Kouzani A.S. 2002. Intelligent Animal Fiber Classification with Artificial Neural Networks, Text. Res. J., 72(7), pp 594-600.

[14] Yazıcı, A. C., Öğüş, E., Ankaralı,S., Vd. 2007. Yapay Sinir Ağlarına Genel Bakış. Turkiye Klinikleri Journal of Medical Sciences 27(1):65-71.

[15] Cheng L., Ghorashi H., Duckett K., Zapletalova T., Watson M. 1999. Color Grading of Cotton Part II: Color Grading with an Expert System and Neural Networks, Text. Res. J., 69(12), pp 893-903.

[16] Xu B., Su J., Dale D.S.. Watson M.D. 2000. Cotton Color Grading with a Neural Network, Text. Res. J., 70(5), pp 430-436.

[17] Kang T.J., Kim S.C. 2002. Objective Evaluation of the Trash and Color of Raw Cotton by Image Processing and Neural Network, Text. Res. J., 72(9), pp. 776-782.

[18] Mwasiagi J. I., Wang X. H., Huang X. B. 2009. The Use of K-means and Artificial Neural Network to Classify Cotton Lint, Fibers and Polymers, Vol.10, No.3, 379-383. 
[19] Allan G., Yang R., Fotheringham A., Mather R. 2001. Neural modelling of polypropylene fibre processing: Predicting the structure and properties and identifying the control parameters for specified fibres, J. of Materials Science, $36 \mathrm{pp}$. $3113-3118$

[20] Kuo C.F.J., Hsiao K.I., Wu Y.S. 2004. Using Neural Network Theory to Predict the Properties of Melt Spun Fibers, Text. Res. J., 74(9), 2004, pp 840-843.

[21] Toprakçı, O. 2008. Ring İplikçiliğinde Lif Özelliklerinden Pamuk İpliği Özelliklerinin Tahminlenmesinin Araştırılması. Pamukkale Üniversitesi, Fen Bilimleri Enstitüsü, Yüksek Lisans Tezi Tekstil Mühendisliği Anabilim Dalı. Denizli,syf 208.

[22] Zeng Y. C., Wang K. F. and Yu C. W. 2004. Predicting the Tensile Properties of Air-Jet Spun Yarns, Textile Research Journal, 74(8), 689-694.

[23] Erol, V., Başlıgil, H. 2005. Analytic Hierarchy Process and Artificial Neural Networks Model for Management Information Systems Software Selection in Companies. Journal of Engineering and Natural Sciences, 4, 107-120.

[24] Majumdar, A., Majumdar, P. K., Sarkar, B. 2005. Application of linear regression, artificial neural network and neuro-fuzzy algorithms to predict the breaking elongation of rotor-spun yarns, Indian Journal of Fibre \& Textile Research, Vol. 30, 19-25.

[25] Tsai, I.S., Lin, C.H., Lin, J.J., 1995. Applying an Artificial Neural Network to Pattern Recognition in Fabric Defects, Textile Research Journal, 65(3), 123-130

[26] Tsai, I.S., Hu, M.C. 1996. Automatic Inspection of Fabric Defects Using an Artificial Neural Network Technique, Textile Research Journal, 66(7), 474482

[27] Bahlmann, C., Heidemann, G., Ritter, H. 1999. ANN For Automated Quality Control Of Textile Seams, Pattern Recognition, 32,1049-1060.

[28] Doğmuş, O., Onat A., Yılmaz, Ş., Ergün, Ş. 2005. Tekstil Fabrikalarındaki Bağıl Nemin Yapay Sinir Ağları Yöntemi İle Kontrolü. KSÜ Fen ve Mühendislik Dergisi 8(1), 53-59

[29] Güneşoğlu, S. 2005. Sportif Amaçlı Giysilerin Konfor Özelliklerinin Araştırılması. Doktora Tezi, Uludağ Üniversitesi, Bursa, Türkiye.

[30] Nasiri, M., Shanbeh, M., Tavanai, H. 2006. "Comparison of Statistical Regression, Fuzzy Regression and Artificial Neural Network Modeling Methodologies in Polyester Dyeing". International Conference on Computational Intelligence for Modelling, Control and Automation and International Conference on Intelligent Agents, Web Technologies and Internet Commerce.
[31] Yürük, N. 2006. \%100 Pamuklu Dokuma Kumaşlara Uygulanan Buruşmazlık Bitim İşlemi Sonrası Kopma Mukavemeti, Aşınma Dayanımı ve Buruşma Açısı Özelliklerinin Yapay Sinir Ağı (ANN) Yöntemi ile Tahminlenmesi. Uludağ Üniversitesi, Fen Bilimleri Enstitüsü, Yüksek Lisans Tezi, 76 s., Bursa.

[32] Hasani, H., Shanbeh, M. 2010. Application of multiple linear regression and artificial neural network algorithms to predict the total hand value of summer knitted T-shirts. Indian Journal of Fibre \& Textile Research Vol. 35, 222-227.

[33] Ierace, S., Pinto, R., Troiano, L., Cavalieri, S. 2010. Neural network as an efficient diagnostics tool: A case study in a textile company. IFAC Proceedings Volumes, 43(3), 122-127.

[34] Sarıdereli, A. 2010. Boyahanelerde Laboratuvar İle İşletme Arasındaki Renk Değişimlerinden Kaynaklanan Hataların Azaltılması. Dokuz Eylül Üniversitesi Fen Bilimleri Enstitüsü, İzmir.

[35] Majumdar A. 2011. Modelling of Thermal Conductivity of Knitted Fabrics Made of CottonBamboo Yarns Using Artificial Neural Network. The Journal of The Textile Institute, 102(9), 752762.

[36] Huang, M. L., Fu, C.C. 2018. Applying Image Processing to the Textile Grading of Fleece Based on Pilling Assessment, Fibers 2018, 6, 73 